\title{
The Parameters Optimizing Design of Double Suspension Arm Torsion Bar in the Electric Sight-Seeing Car by Random Vibration Analyzing Method
}

\author{
Shui-Ting Zhou, ${ }^{1,2}$ Yi-Jui Chiu, ${ }^{2,3}$ and I-Hsiang Lin ${ }^{4,5}$ \\ ${ }^{1}$ State Key Laboratory of Advanced Design and Manufacturing for Vehicle Body, Hunan University, Changsha 410082, China \\ ${ }^{2}$ School of Mechanical and Automotive Engineering, Xiamen University of Technology, Xiamen, Fujian 361024, China \\ ${ }^{3}$ State Key Laboratory for Strength and Vibration of Mechanical Structures, Xian Jiaotong University, No. 28, Xianning West Road, \\ Xian 710049, China \\ ${ }^{4}$ School of Economics and Management, Xiamen University of Technology, Fujian, China \\ ${ }^{5}$ Fujian Key Laboratory of Advanced Design and Manufacture for Bus, Fujian, China \\ Correspondence should be addressed to Yi-Jui Chiu; chiuyijui@xmut.edu.cn
}

Received 28 March 2017; Accepted 27 June 2017; Published 12 September 2017

Academic Editor: Matteo Filippi

Copyright (C) 2017 Shui-Ting Zhou et al. This is an open access article distributed under the Creative Commons Attribution License, which permits unrestricted use, distribution, and reproduction in any medium, provided the original work is properly cited.

This study is about the impact of the performance and the sensitivity analysis for parameters of the torsion bar suspension in the electric sight-seeing car, which the authors' laboratory designed and which is used in the authors' university. The suspension stiffness was calculated by using the virtual work principle, the vector algebra, and tensor of finite rotation methods and was verified by the ADAMS software. Based on the random vibration analysis method, the paper analyzed the dynamic tire load (DTL), suspension working space (SWS), and comfort performance parameters. For the purpose of decreasing the displacement of the suspension and limiting the frequency of impacting the stop block, the paper examined the three parameters and optimized the basic parameters of the torsion bar. The results show that the method achieves a great effect and contributes an accurate value for the general layout design.

\section{Introduction}

The common problems of vehicles, including suspension static deformation, front suspension weakness, tendency of frequently hitting stop blocks, and location angle of front wheels changing out of its limits, are mainly caused by excessively low biased frequency design value and suspension stiffness.

Since the year 2000, some conference papers focus on small but specific studies; Wang et al. [1] explored kinematics characteristics of suspension with double trailing arms for light off-road vehicles; they found that the double trailing arm lengths, the angles between double trailing arms, horizontal/vertical plane, and bushing stiffness of the double trailing arms linking with frame are four major parameters that affect the caster and front-wheel steering angle. Tian et al. [2] optimized analysis of the wheeled armored vehicle double wishbone independent suspension system. Guo and Sun [3] simulated model of the double wishbone independent front suspension with a single degree of freedom. Through the optimization and analysis of the upper cross arm and the low cross arm, they observed the goal of decreasing the sideways displacement and the tire wear. Cherian et al. [4] developed a nonlinear model of a double wishbone suspension and investigated the effects of variation of suspension parameter on the transmission and distribution of tire forces acting on the wheel spindle to the steering system and the vehicle chassis. Burgess et al. [5] described the development of a vehicle suspension analysis tool; they selected points and set tolerances to study the suspension model system in the interaction environment. Mohamad and Farhang [6] built a $2 \mathrm{D}$ suspension tire system model and investigated the dynamic interaction between the suspension and the tire of an automotive system. 


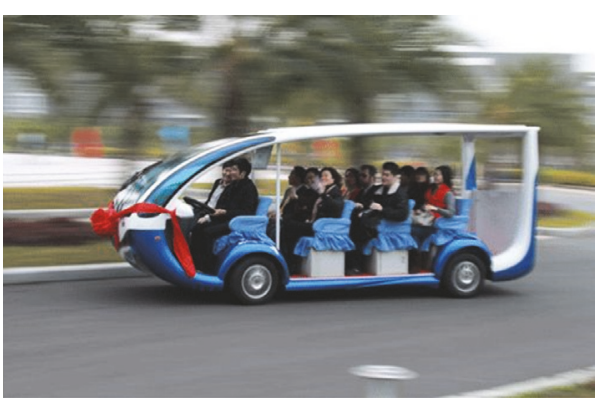

(a)

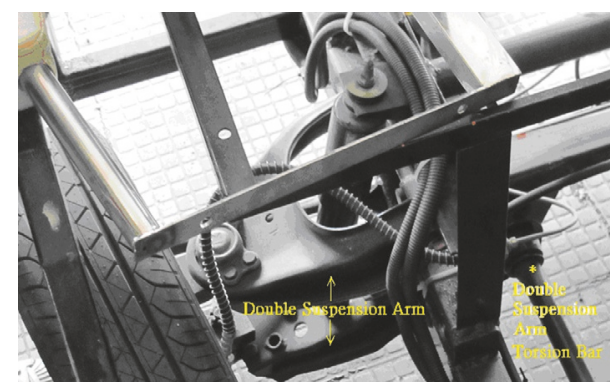

(b)

Figure 1: (a) The electric sight-seeing car; (b) the double suspension arm torsion bar of car.

Linear or nonlinear 2-DOF quarter-car models have been widely used to study the conflicting dynamic performances of a vehicle suspension. In recent years, Balike et al. [7] built the formulation of a comprehensive kinetic-dynamic quarter-car model to study the kinematics and dynamic properties of a linkage suspension. Zhao et al. [8] studied the lower control arm of front suspension; they optimized original structure and observed that the strength and stiffness were increased significantly while the mass was almost unchanged. Wang et al. [9] developed a model and calculation method for obtaining the joint forces and moments for a multilink suspension. Tang et al. [10] proposed and developed a modeling and calculation method for obtaining the forces applied to the ball joints and the bushings and moments applied to the bushings. The calculation and comparison demonstrate that the bushing nonlinear and rotational stiffness must be modeled for precise calculation of ball joint force and moments. Liu and Zhao [11] took an optimization design of the incompatibility of the movement between suspension and steering linkage, and the trend of tires' nonpure rolling, to reduce the tires' wear and improve the moving compatibility between suspension and steering system. Sun et al. [12] designed and strengthened analysis of FSAE suspension. Kang et al. [13] presented a comprehensive analysis of different independent front suspension linkages that have been implemented in various off-road vehicles, including a composite linkage, a candle, a trailing arm, and a double wishbone suspension applied to a truck. Design, fabrication, and testing of the suspension subsystem by Das et al. [14] had double wishbone geometry for the front half of the car and a semitrailing arm geometry for the rear half. Wu et al. [15] proposed a new design optimization framework for suspension systems considering the kinematics characteristics. The results showed the effectiveness of the proposed design method. Kang et al. [16] investigated relative kinematics properties of four different independent front axial suspensions.

In all researches mentioned above, they did not input the road situation as random vibration. However, the real road situation is random. In this paper, suspension stiffness was calculated with principle of virtual work and the result was verified from result simulation in ADAMS. Considering the road situation as random vibration, the power spectral function was used to establish correlation function as one of constraint conditions to optimize calculating basic size of torsion bar for increasing suspension stiffness, decreasing frequency of hitting stop block, and meanwhile limiting the change of location angle of front wheels.

\section{Establishing a Mathematical Model}

Based on the electric sight-seeing car (Kin-Xia, No. 1, in Figure 1(a)), which the authors' laboratory designed and which is used in the authors' university, the authors established a mathematical model of double-arm torsion bar suspension guide mechanism kinematics, as shown in Figure 1(b). The guide mechanism of double-arm suspension is considered as a spatial four-bar mechanism. The suspension guide rob kinematics relations are established with transcendental equation of input axis turning angle and output turning angle calculated with MVA combined with finite rotation tensor method. The variation function of hard spots is obtained through geometrical relationship. The arms under suspension are connected with spindle 1 and the upper arms $C D$ are connected with spindle 2 with the steering knuckle link point of point $E$ in Figure 2. $\bar{p}, \bar{q}$ of unit vectors are defined as forward direction rotating along spindle 1 and spindle 2 separately. The $\alpha$ angle is the rotation angle of upper arms $C D$ moving around spindle 2 with the rotation center of point $C$. The upper arms $C D$ are denoted as $C D^{\prime}$ after rotation. The $\beta$ angle is the rotation angle of nether arms $A B$ moving around spindle 1 with the rotation center of point $A$. The nether arms $A B$ are denoted as $A B^{\prime}$ after rotation. $O^{\prime}$ is the wheel center and $E$ point is the intersection of wheel centerline extension and the virtual swizzle link $D B$.

Next, we solved the hard point of guide mechanism in the process of suspension movement. The first step is to solve the point coordinate of exterior ball joints of upper arms. $D$ point coordinate is solved according to geometric characteristics since the upper exterior point $D$ only rotates around spindle 2 in the process of bobbling. The coordinate variation function is obtained according to vector method:

$$
\left[x_{D}, y_{D}, z_{D}, 1\right]=H_{o, c} \times H_{1}^{-1} \times H_{Z} \times H_{1} \times H_{c, 0} .
$$




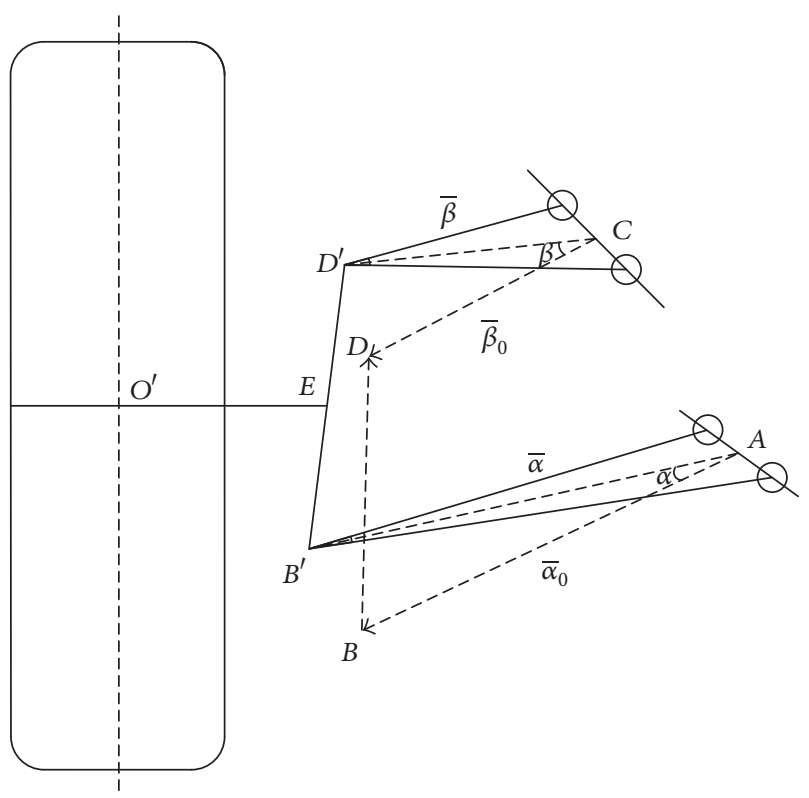

FIGURE 2: Structure diagram of double suspension arm.

The displacement transformation matrixes of the point $C$ coordinate system to the point $O$ coordinate of full vehicle are

$$
H_{c, 0}=\left[\begin{array}{cccc}
1 & 0 & 0 & 0 \\
0 & 1 & 0 & 0 \\
0 & 0 & 1 & 0 \\
x_{c} & y_{c} & z_{c} & 1
\end{array}\right]
$$

The displacement transformation matrix of rotational angle is obtained with $-\beta_{o^{\prime}}$ as the rotational angle of $C$ point coordinate system moving around the $y$-axis of $O$ point coordinate system and $-\alpha_{o^{\prime}}$ as rotational angle around $z$-axis:

$$
H_{1}=\left[\begin{array}{cccc}
\cos \beta_{o^{\prime}} \cos \alpha_{o^{\prime}} & \cos \beta_{o^{\prime}} \sin \alpha_{o^{\prime}} & \sin \beta_{o^{\prime}} & 0 \\
\sin \alpha_{o^{\prime}} & \cos \alpha_{o^{\prime}} & 0 & 0 \\
\sin \beta_{o^{\prime}} \cos \alpha_{o^{\prime}} & \sin \beta_{o^{\prime}} \sin \alpha_{o^{\prime}} & \cos \beta_{o^{\prime}} & 0 \\
0 & 0 & 0 & 1
\end{array}\right]
$$

With $\beta$ as the rotational angle of upper arms around spindle 2 ,

$$
H_{z}=\left[\begin{array}{cccc}
1 & 0 & 0 & 0 \\
0 & \cos \beta & \sin \beta & 0 \\
0 & -\sin \beta & \cos \beta & 0 \\
0 & 0 & 0 & 1
\end{array}\right]
$$

The point coordinate of exterior ball joints is obtained.

Then, we solved the point coordinate of exterior ball joints of nether arms. $B$ point coordinate is obtained in the same way since the nether outer point $B$ is rotating around spindle 1 in the process of bobbling.

The displacement equation of wheel centers is obtained. Since the distances between wheel centers and upper or

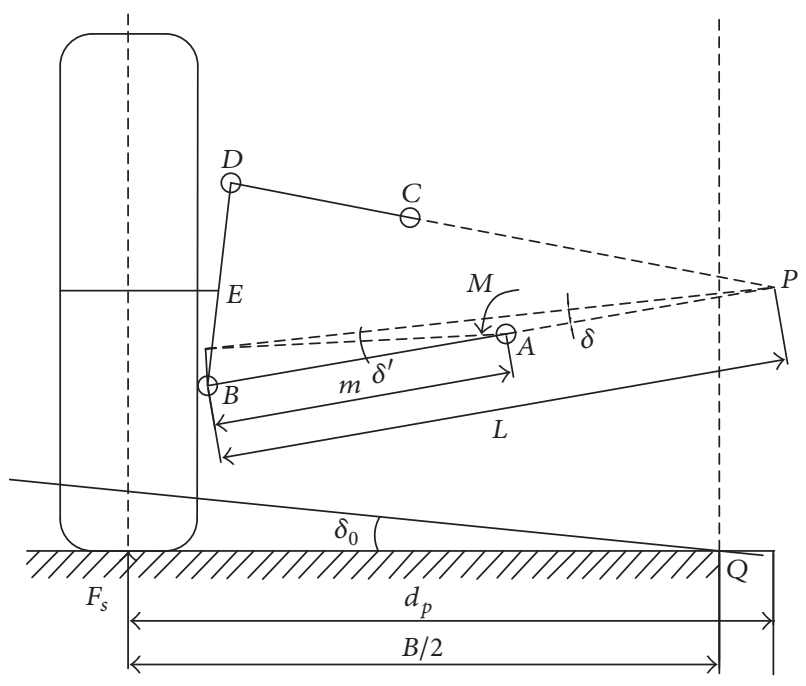

FIGURE 3: Force model of the suspension.

nether arm points of suspensions and central points of steering knuckles are invariant according to the structure dimension separately, the $O^{\prime}$ coordinate is obtained on the basis of vector module invariance. The mathematical expression of the coordinate of $O^{\prime}$ as the center point of the wheel is as follows:

$$
\sum\left(\Gamma_{o^{\prime}}-\Gamma_{i}\right)=d_{o^{\prime} i}^{2}, \quad \Gamma=(x, y, z), i=(B, D, E),
$$

where $d_{o^{\prime} i}$ is the distance and $x_{i}, y_{i}$, and $z_{i}, i=\left(O^{\prime}, B, D, E\right)$, are the coordinates of corresponding points in the full vehicle coordinate system; that is,

$$
\begin{aligned}
& \left(x_{o^{\prime}}-x_{B}\right)^{2}+\left(y_{o^{\prime}}-y_{B}\right)^{2}+\left(z_{o^{\prime}}-z_{B}\right)^{2}=d_{o^{\prime} B}^{2} \\
& \left(x_{o^{\prime}}-x_{D}\right)^{2}+\left(y_{o^{\prime}}-y_{D}\right)^{2}+\left(z_{o^{\prime}}-z_{D}\right)^{2}=d_{o^{\prime} D}^{2} \\
& \left(x_{o^{\prime}}-x_{E}\right)^{2}+\left(y_{o^{\prime}}-y_{E}\right)^{2}+\left(z_{o^{\prime}}-z_{E}\right)^{2}=d_{o^{\prime} E}^{2}
\end{aligned}
$$

The coordinate of $O^{\prime}$ as the center point of the wheel is obtained.

The vertical displacement variation is expressed as

$$
d f=\Delta s=\Delta z_{o^{\prime}}=\left(z_{o^{\prime} 1}-z_{o^{\prime} 2}\right),
$$

where $z_{o^{\prime} 1}, z_{o^{\prime} 2}$ are the $z$-axis coordinates of the central point of wheel.

This paper also used virtual work principle to solve the stiffness of suspensions. The spring stiffness of double-arm independent suspension is assumed with a virtual stiffness of $C_{s}$ acting on wheels vertically, with $P$ point as intersection of upper and nether arm extension lines separately, $l$ as distance between intersection $p$ to $B$ point of the nether arm, $m$ as length of the nether arm, $p$ as horizontal range from the intersection to the ground connection point of the wheel, $B$ as wheel span, and $C_{T}$ as stiffness of torsion bars. These are shown in Figure 3.

According to the virtual work principle, the rotational virtual angle of the force $F_{s}$ acting on the terrain point $Q$ is $\delta_{\Phi}$, 


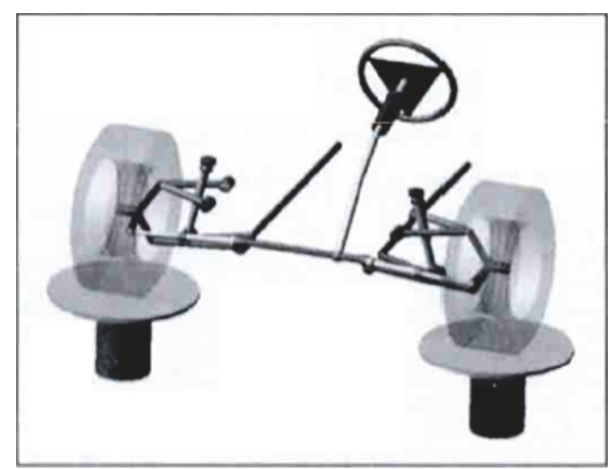

Figure 4: The dynamic model of front suspension and steering system by ADAMS.

and the rotational virtual angle of the nether arm suspension around point $A$ is $\delta^{\prime}$; then

$$
\begin{aligned}
F_{s} \cdot \frac{B}{2} \cdot \delta_{\Phi} & =M \cdot \delta^{\prime}=F_{s} \cdot p \cdot \delta, \\
M & =C_{T}(\varphi-\alpha) .
\end{aligned}
$$

$\alpha$ is the initial angle of the torsion bar and $\varphi$ is the postrotation angle of the torsion bar in the above functions.

According to geometrical relationship,

$$
\delta^{\prime} \cdot m=\delta \cdot l
$$

The vertical force that acted on the wheel is solved as

$$
C_{s}=\frac{d F}{d f}=\frac{d F}{d \varphi} \cdot \frac{d \varphi}{d f} .
$$

\section{Simulation Model of Front Suspension and Steering System Establish by ADAMS}

The entity structure of automobile front suspension is more complicated. In order to establish a reasonable model, this paper simplified and assumed the suspension as follows: (1) All components of the system are rigid bodies; (2) all connections between components in the system are simplified as hinges; (3) internal clearance is negligible; (4) ignoring the deformation of the guide rod and the absorber is simplified to a damping and linear spring; (5) the friction force between the kinematic pairs in the system is ignored, and the connection between the motion pairs is rigid; (6) the body of the car does not move relative to the ground and the tire is simplified as a rigid body. In the modeling, the opposite direction of the vehicle is the $x$-axis, the left side of the car is the $y$-axis, and the vertical upward direction is the $z$-axis. This research builds double wishbone torsion bar suspension system and steering system in the ADAMS/Car standard mode. Then, on the basis of the system model established by the template, the coordinate values of the system model are modified according to the hard point coordinates as shown in Table 1.

\begin{tabular}{|c|c|c|c|}
\hline Hard point & $\begin{array}{c}X \\
\text { coordinate } \\
\end{array}$ & $\begin{array}{c}Y \\
\text { coordinate }\end{array}$ & $\begin{array}{c}Z \\
\text { coordinate }\end{array}$ \\
\hline $\begin{array}{l}\text { Torsion bar } \\
\text { Fulcrum }\end{array}$ & 950.0 & -237.0 & -49.0 \\
\hline $\begin{array}{l}\text { Lower control arm } \\
\text { Front fulcrum }\end{array}$ & -53.7 & -237.0 & -49.0 \\
\hline $\begin{array}{l}\text { Lower control arm } \\
\text { Outside fulcrum }\end{array}$ & -5.0 & -594.0 & -103.5 \\
\hline $\begin{array}{l}\text { Lower absorber } \\
\text { Mounting point }\end{array}$ & -3.7 & -457.0 & -63.3 \\
\hline $\begin{array}{l}\text { Inner spherical head } \\
\text { Point }\end{array}$ & -104.5 & -257.0 & -6.6 \\
\hline $\begin{array}{l}\text { Outer spherical head } \\
\text { Point }\end{array}$ & -119 & -631.5 & -32.8 \\
\hline $\begin{array}{l}\text { Upper absorber } \\
\text { Mounting point }\end{array}$ & -3.7 & -380.6 & 236.0 \\
\hline $\begin{array}{l}\text { Upper control arm } \\
\text { Front fulcrum }\end{array}$ & -94.0 & -353.4 & 110.0 \\
\hline $\begin{array}{l}\text { Upper control arm } \\
\text { Outer fulcrum }\end{array}$ & 6.5 & -567.5 & 116.0 \\
\hline $\begin{array}{l}\text { Upper control arm } \\
\text { Back fulcrum }\end{array}$ & 106.0 & -353.4 & 110.0 \\
\hline Wheel center & 0.0 & -690.0 & -2.0 \\
\hline
\end{tabular}
The dynamic model of the double wishbone torsion bar suspension and steering system is shown in Figure 4.
TABLE 1: The hard point coordinates of front suspension.

Figure 5 shows that the ADAMS emulation result is similar to the result calculated mathematically in MATLAB with an error range within $\pm 10 \%$ in the bobbling process of $\pm 60 \mathrm{~mm}$. The error is mainly caused by the stiffness change of rubber boot outside the range of $\pm 20 \mathrm{~mm}$. This figure indicates that our mathematical model is feasible within normal range of bobbling.

\section{Analyzing the Influence of Torsion Bar on Suspension Stiffness}

The suspension stiffness is nonlinear based on the nonlinearity of the movement of space guidance mechanism in the process of tire bobbling. The variation tendency of frontwheel alignment parameters is relatively small in order to ensure the suspension bobbling confirming demand of the arrangement design. On the condition that the coordinate of suspension hard point is invariant, $d$ as the diameter torsion bar, along with $L_{e}$ as the torsion bar effective length, and $\alpha$ as pretwist angle are analyzed. The swing arm length of nether arms is not analyzed as an effect variable in this paper because changing the swing arms of nether arms is equal to changing the suspension hard point which involves the coordination of hard points of suspension and steering.

The influence of parameter on suspension stiffness is shown in Figure 6, and the parameter variation ranges are $\pm 10 \%$. Taking full-load suspension stiffness as assessment criteria, the variable value of stiffness is $15 \%$ with the torsion 


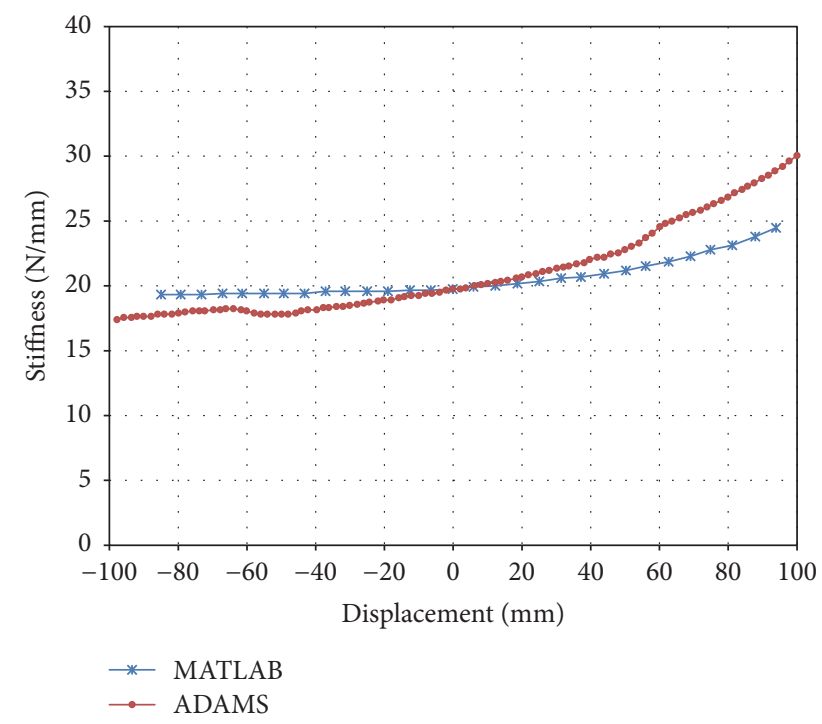

FIGURE 5: Stiffness curve of the suspension.

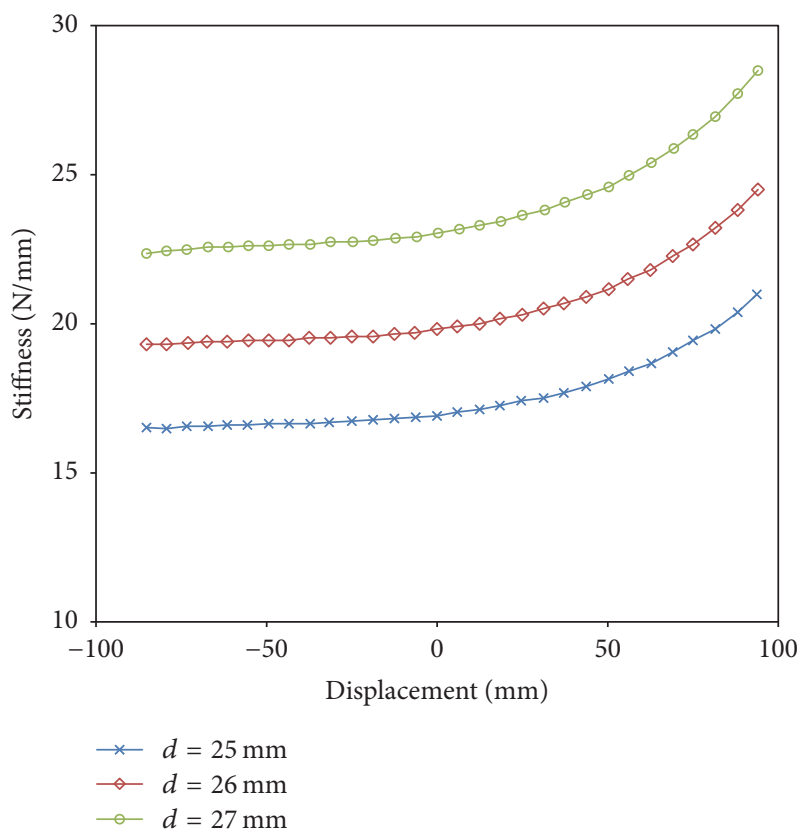

FIGURE 6: Stiffness curve of the suspension with variable diameter.

bar diameters of $25 \mathrm{~mm}, 26 \mathrm{~mm}$, and $27 \mathrm{~mm}$, respectively, and with the diameter variable value of $3.85 \%$ compared with the median of $26 \mathrm{~mm}$.

Figure 7 shows stiffness curve of the suspension with variable length. The effective lengths of torsion bar are $913.5 \mathrm{~mm}, 950 \mathrm{~mm}$, and $986.5 \mathrm{~mm}$, respectively, with the variable value of $3.85 \%$ compared with median value. The stiffness variable value of full-loan suspension is $2.56 \%$.

Figure 8 shows stiffness curve of the suspension with variable angle. The pretwist angle has no influence on suspension stiffness in fact with the torsion bar pretwist angle of $8.41^{\circ}, 8.57^{\circ}$, and $9.09^{\circ}$ with the variable value of $3.85 \%$ compared with median value. It is probably because

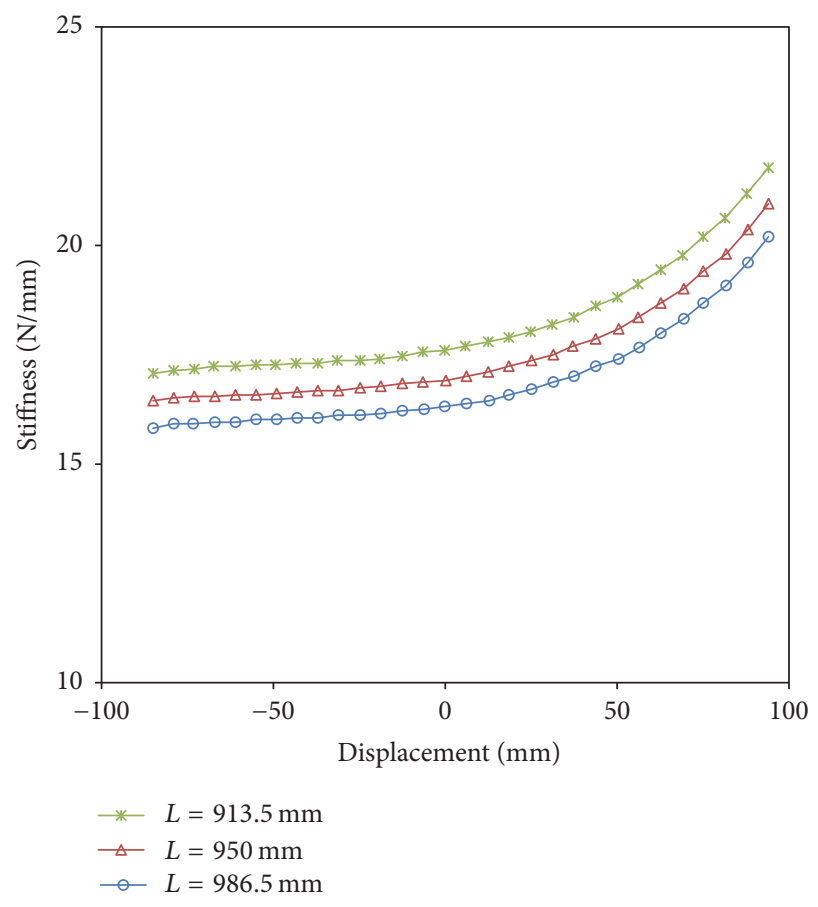

FIGURE 7: Stiffness curve of the suspension with variable length.

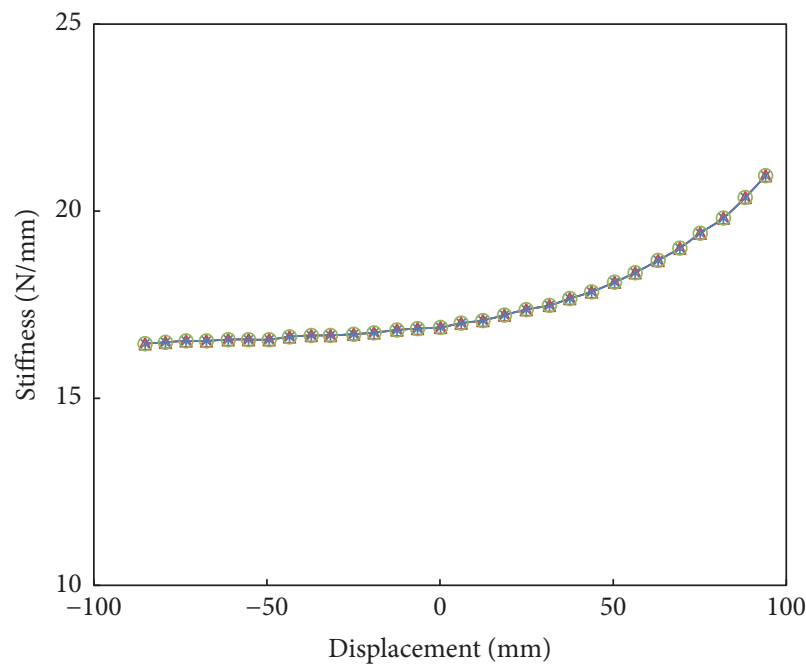

$$
\begin{aligned}
\rightarrow \text { Alfa } & =8.41^{\circ} \\
\triangle & \text { Alfa }=8.75^{\circ} \\
- \text { Alfa } & =9.09^{\circ}
\end{aligned}
$$

Figure 8: Stiffness curve of the suspension with variable angle.

the change of pretwist angle actually changes the working state of suspension nether arms and adjusts the position of initial state of suspension space; that is, it changes the working interval instead of suspension stiffness curve.

It can be concluded from the above analysis that the parameters with greater influences on suspension stiffness include $d$ as diameter of torsion bar and $L_{e}$ as effective length of torsion bar. Considering limits of the general arrangement and the changes of nether arms involving redesign of hard 


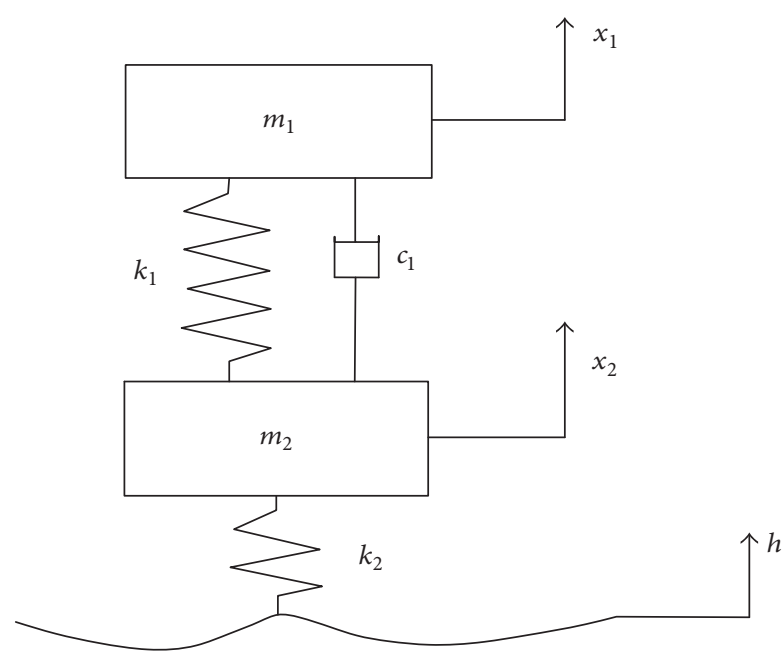

Figure 9: 1/4 physical model of the vehicle.

points, both $d$ as diameter of torsion bar and $L_{e}$ as effective length of torsion bar are selected as efficient variables for optimizing in this paper.

\section{Establishing the Optimizing Mathematical Model}

The problems in the test run include the obvious parameter variation of front-wheel alignment and great variation of vehicle height caused by frontier suspension softness and excessive wheel bobbling separately. The suspension stiffness is optimized and the diameter and effective length of torsion bar are selected appropriately with the optimizing target of vertical displacement variations of suspension from zero loads to no load and from no load to full load combined with dynamic load of tires and riding comfort parameters in this paper.

First, the authors established the constrained function of suspension performance parameters. The evaluation index formula is established and dynamic rate parameters of suspension are analyzed from the perspective of riding safety and comfort. The performance in the working condition of no load (drivers included), half load, and full load is analyzed with the evaluation index of power spectral density in frequency domain and with the introduction of new objective function method.

The $1 / 4$ vehicle model is established as demonstrated in Figure 9 with $h$ as road input, $k_{1}, k_{2}$ as suspension stiffness and tire stiffness separately, $c_{1}$ as suspension damping factor, $m_{1}$ as body mass, $m_{2}$ as wheel mass, $x_{1}$ as body displacement, and $x_{2}$ as wheel displacement

Establish a corresponding state space equation

$$
\begin{aligned}
& \dot{X}=A X+B U, \\
& Y=C X+D U .
\end{aligned}
$$

The state parameters are

$$
X=\left[\begin{array}{llll}
x_{1} & x_{2} & \dot{x}_{1} & \dot{x}_{2}
\end{array}\right]^{T} .
$$

The output variances are

$$
\begin{aligned}
& Y=\left[\begin{array}{lll}
F_{Z} & \ddot{x}_{1} & x_{1}-x_{2}
\end{array}\right]^{T}, \\
& A=\left[\begin{array}{cccc}
0 & 0 & 1 & 0 \\
0 & 0 & 0 & 1 \\
-\frac{k_{1}}{m_{1}} & \frac{k_{1}}{m_{1}} & -\frac{c_{1}}{m_{1}} & \frac{c_{1}}{m_{1}} \\
\frac{k_{1}}{m_{2}} & -\frac{k_{1}+k_{2}}{m_{2}} & \frac{k_{1}}{m_{2}} & \frac{k_{1}}{m_{2}}
\end{array}\right] \text {, } \\
& B=\left[\begin{array}{c}
0 \\
0 \\
0 \\
-\frac{k_{2}}{m_{2}}
\end{array}\right] \\
& C=\left[\begin{array}{cccc}
0 & -k_{2} & 0 & 0 \\
1 & -1 & 0 & 0 \\
-\frac{k_{1}}{m_{1}} & \frac{k_{1}}{m_{1}} & -\frac{c_{1}}{m_{1}} & \frac{c_{1}}{m_{1}}
\end{array}\right] \text {, } \\
& D=\left[\begin{array}{c}
0 \\
0 \\
-\frac{k_{2}}{m_{2}}
\end{array}\right] \text {. }
\end{aligned}
$$

The road input $h$ is a spectral density function.

$$
\Phi_{h}(\Omega)=\Phi_{h}\left(\Omega_{0}\right)\left[\frac{\Omega}{\Omega_{0}}\right]^{-w},
$$

where $\Omega_{0}$ is the standard travel circular frequency, $\Phi_{h}\left(\Omega_{0}\right)$ is the scale of road roughness, and $w$ is the scale of waviness. The road condition is relatively good considering the driving condition as schoolyards and tourist attractions. The pavement is comparatively flat and the jerk value is comparatively low with the reference input of $B$ scale pavement. Next, the speed of a campus car is comparatively low because of the speed limit. The vehicle speed $v$ here is set as $10 \mathrm{~m} / \mathrm{s}$.

The road spectrum travel power is transformed into time domain power spectrum as

$$
\Phi_{h}(w)=\frac{1}{v} \Phi_{h}(\Omega) .
$$

The standard deviation of evaluation criteria is obtained on the basis of amplitude-frequency characteristic of road spectrum and vibration parameters.

The scales of driving safety of cars are defined as the root mean square of weighed acceleration of vertical accelerometer.

$$
\begin{aligned}
K_{\text {Foot }}^{2} & =\int_{0}^{50 \pi} \Phi_{K \text { foot }} d w \\
& =\int_{0}^{50 \pi} B_{\text {foot }}^{2}\left[\frac{\ddot{x}_{1}(w)}{h(w)}\right]^{2} \Phi_{k}(w) d w,
\end{aligned}
$$

where $B_{\text {foot }}^{2}$ is the evaluation index. 
TABLE 2: Correction coefficients.

\begin{tabular}{lcc}
\hline $\begin{array}{l}\text { Vibration action point and } \\
\text { direction }\end{array}$ & $\begin{array}{c}\text { Random } \\
\text { correction } \\
\text { coefficient }\end{array}$ & $\begin{array}{c}\text { Multicoordinate } \\
\text { correction } \\
\text { coefficient }\end{array}$ \\
\hline$Z$ direction of seat & 1.26 & 1.1 \\
$Z$ direction of foot & 1.26 & 1.3 \\
$Z$ direction of hand & 1.26 & 0.75 \\
$X$ and $Y$ direction of seat & 1.23 & 1.47 \\
$X$ direction of back seat & 1.25 & 1.09 \\
$X$ and $Y$ direction of foot & 1.28 & 1.28 \\
Pitching motion & 1.23 & 1.16 \\
Roll motion & 1.23 & 0.98 \\
\hline
\end{tabular}

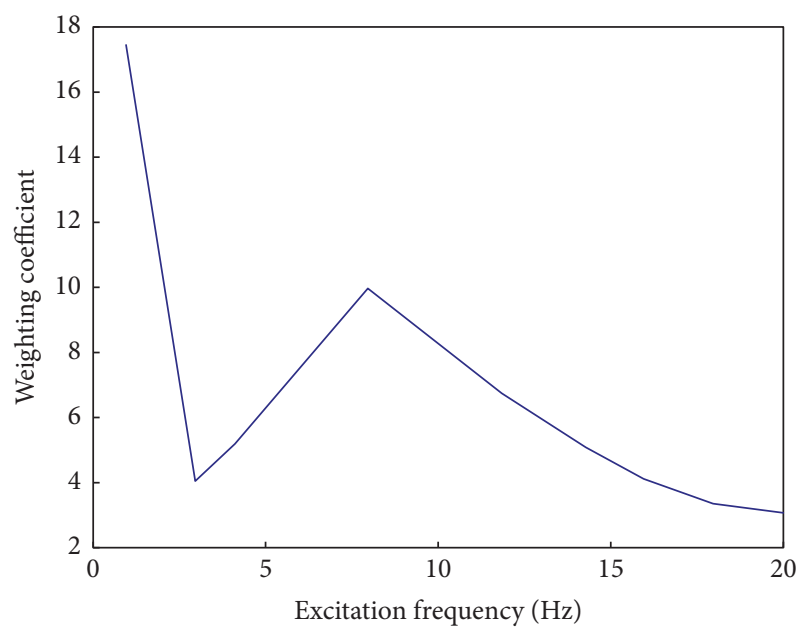

FIGURE 10: Evaluation value of the vibration.

Since the frequency range of random vibration is wide and random vibration brings more discomfort than harmonic vibration, for this reason, an evaluation function is introduced in Figure 10, and $B_{\text {foot }}=\zeta_{i} B_{m}$, where $\zeta_{i}$ is random correction factor as shown in Table 2.

The vibration analysis in the mathematical model of this paper is mainly focused on $z$ orientation of feet. Corresponding parameters are selected according to the above icons.

Evaluation index of suspension dynamic travel is defined as quadratic mean of difference between wheel displacement and body displacement, the difference of displacement variation caused by road surface irregularity on the condition of invariant load.

$$
\begin{aligned}
\text { SWS } & =\int_{0}^{50 \pi} \Phi_{\text {SWS }}(w) \\
& =\int_{0}^{50 \pi}\left[\frac{x_{1}(w)-x_{2}(w)}{h(w)}\right]^{2} \Phi_{h}(w) d w .
\end{aligned}
$$

The two parameters listed below are taken as objective function since the suspension bobbling travel is excessively long and the body height variation is excessively obvious in the trial-production process:
TABLE 3: The optimized result.

\begin{tabular}{lr}
\hline Torsion bar diameter & $26.5 \mathrm{~mm}$ \\
Torsion bar effective length & $895 \mathrm{~mm}$ \\
\hline
\end{tabular}

(1) The vertical displacement variation of nether ball joint point from zero load to full load is

$$
\Delta S=S_{\text {zerozai }}-S_{\text {kongzai }}
$$

(2) The vertical displacement variation of nether ball joint point from empty load to full load is

$$
\Delta S=S_{\text {manzai }}-S_{\text {kongzai }}
$$

Next, the authors determined the constraint:

(1) The longitudinal set of torsion bar is decided by the spatial arrangement of general arrangement. The lengths of torsion bar $\left(L_{e}\right)$ in the long direction are limited in the range of $800 \mathrm{~mm}$ to $1000 \mathrm{~mm}$.

(2) Considering the height limit of the distance to nether surface of the frame, the diameters of torsion bar are limited to the range of $0<d<40$.

(3) The diameters are selected within integers or nonintegers with decimal parts of 0.5 .

(4) The torsion bar is made of $45 \mathrm{CrNiMoVa}$ alloy steel with good quality.

(5) The allowable stress of the torsion bar $\left[\tau_{s}\right]$ is within the range of 1000 to $1250 \mathrm{~N} / \mathrm{mm}^{2}$.

(6) The possibility of hitting a stock is comparatively small since the SWS variation of suspension dynamic travel variation is comparatively small.

The optimized result is obtained with the MATLAB nonlinear multitarget optimizing tool box, which is shown in Table 3. The torsion bar diameter is set to be $26.5 \mathrm{~mm}$; the torsion bar effective length is set to be $895 \mathrm{~mm}$.

\section{Analysis of Optimized Result}

In Table 4, the optimized result is also obtained with the MATLAB nonlinear multitarget optimizing tool box; we noticed the following:

(1) Before optimizing, the vertical displacement variation of swizzle nether ball joint points from suspension zero load to suspension empty load is $77.5 \mathrm{~mm}$ and the vertical displacement variation from empty load to full load is $88 \mathrm{~mm}$ before optimizing. After optimizing, the vertical displacement variation of swizzle nether ball joint points from suspension zero load to suspension empty load becomes $70 \mathrm{~mm}$ and the vertical displacement variation from empty load to full load becomes $76.5 \mathrm{~mm}$; the value of vertical displacement variation is $9.67 \%$ and $13.1 \%$, respectively, less than the original value. 
TABLE 4: Property parameter before and after optimization.

\begin{tabular}{lcccc}
\hline & \multicolumn{2}{c}{ Property parameter before and after optimization } & & \\
& Optimization & $F_{Z}(\mathrm{~N})$ & SWS $(\mathrm{m})$ & $K_{\text {foot }}($ dimensionless $)$ \\
\hline \multirow{2}{*}{ Empty load (with driver) } & Before & 92.27 & 0.0019 & 2.9586 \\
& After & 92.96 & 0.0019 & 3.0870 \\
Half load & Before & 94.16 & 0.0023 & 2.6229 \\
& After & 95.36 & 0.0023 & 2.7706 \\
Full load & Before & 97.95 & 0.0026 & 2.4907 \\
& After & 100.5 & 0.0026 & 2.6803 \\
\hline
\end{tabular}

(2) The variation of tire dynamic load of three assessment indices is $1.35 \%$ and the comfort parameter variation is $5.83 \%$. The suspension dynamic travel is basically invariant based on the good condition of campus roads as driving road.

(3) The suspension softness is effectively reduced on the condition that there is almost no effect on the suspension performance.

\section{Conclusion}

The stiffness of double-arm torsion bar suspension in the electric sight-seeing car is calculated with vector algebra combined with virtual work principle and finite tensor method and is tested with ADAMS software to prove the feasibility of mathematical calculating method in this paper. The effect of torsion bar basic parameters on suspension stiffness is analyzed through calculation and the parameters needing optimizing are obtained through sensitivity analysis.

The tire dynamic load is proposed according to the actual condition of driving road. The new evaluation function and index are established with the constraint condition of suspension dynamic travel and comfort parameters and the objective function of suspension jerk value and the optimizing model of torsion bar basic size of double-arm torsion bar suspension is established.

The torsion bar basic size which is optimized with MATLAB multitarget optimizing tool box decreases vertical displacement travel by $9.67 \%$ from suspension zero load to empty load and vertical displacement travel by $13.1 \%$ from suspension empty load to full load. The optimized size increases suspension stiffness effectively and reduces the phenomenon of suspension blocks being hit, restricts the variation of front-wheel alignment angle, and meanwhile effectively improves the phenomenon of frontier suspension softness on the condition of no effects on suspension performance.

\section{Conflicts of Interest}

This manuscript did not lead to any conflicts of interest regarding the publication.

\section{Acknowledgments}

This work was supported by the Fujian Nature Foundation, no. 2016J01039; Xiamen City Project no. 3502Z20173037; and
National Natural Science Foundation of China under Grant nos. 51475399 and 51405410.

\section{References}

[1] R. L. Wang, J. Z. Zhao, G. Y. Wang, X. K. Chen, and L. Li, "Modeling and kinematics simulation analyze of conventional suspension with double trailing arms for light off-road vehicles," Applied Mechanics and Materials, vol. 312, pp. 673-678, 2013.

[2] G. Tian, Y. Zhang, J.-H. Liu, and X.-J. Shao, "Double wishbone independent suspension parameter optimization and simulation," Applied Mechanics and Materials, vol. 574, pp. 109-113, 2014.

[3] Z. Z. Guo and Y. F. Sun, "Optimization and analysis of double wishbone independent front suspension based on virtual prototype," Applied Mechanics and Materials, vol. 490-491, pp. 832835, 2014.

[4] V. Cherian, I. Haque, and N. Jalili, "Development of a non-linear model of a double wishbone suspension for the characterization of force transmission to the steering column and chassis," in Proceedings of the 2004 ASME International Mechanical Engineering Congress and Exposition, IMECE, pp. 775-780, Anaheim, Ca, USA, November 2004.

[5] M. J. Burgess, N. P. Fleming, M. Wootton, and S. J. Williams, "A tool for rapid vehicle suspension design," SAE Technical Papers, 2004.

[6] N. Mohamad and K. Farhang, "A vibration model of a suspension-Tire system," in Proceedings of the ASME Design Engineering Technical Conferences and Computers and Information in Engineering Conference, vol. 2B, pp. 1465-1476, Salt Lake City, Utah, USA, 2004.

[7] K. P. Balike, S. Rakheja, and I. Stiharu, "Development of kinetodynamic quarter-car model for synthesis of a double wishbone suspension," Vehicle System Dynamics, vol. 49, no. 1-2, pp. 107128, 2011.

[8] L. Zhao, S. Zheng, J. Feng, and Q. Hong, "Dynamic structure optimization design of lower control arm based on ESL," Research Journal of Applied Sciences, Engineering and Technology, vol. 4, no. 22, pp. 4871-4878, 2012.

[9] X.-L. Wang, L. Dai, and W.-B. Shangguan, "Calculation of joint forces of a multi-link suspension for strength and fatigue analysis of bushings and control arms," International Journal of Vehicle Design, vol. 66, no. 3, pp. 217-234, 2014.

[10] L. Tang, W.-B. Shangguan, and L. Dai, "A calculation method of joint forces for a suspension considering nonlinear elasticity of bushings," Proceedings of the Institution of Mechanical Engineers, Part K: Journal of Multi-body Dynamics, vol. 226, no. 4, pp. 281297, 2012. 
[11] Z. Liu and L. Zhao, "Motion compatibleness analysis and optimization of double front axle steering mechanism and suspension system," China Mechanical Engineering, vol. 24, no. 16, pp. 2164-2167, 2013.

[12] L. Sun, Z. Deng, and Q. Zhang, "Design and strength analysis of FSAE suspension," Open Mechanical Engineering Journal, vol. 8, article A414, pp. 414-418, 2014.

[13] Y. Kang, S. Rakheja, and W. Zhang, "Relative performance analyses of independent front axle suspensions for a heavyduty mining truck," SAE International Journal of Commercial Vehicles, vol. 7, no. 2, 2014.

[14] A. Das, N. Unnikrishnan, B. Shankar, and J. D. Freeman, "Design, fabrication and testing of the suspension subsystem of a single seater off-road buggy," International Journal of Applied Engineering Research, vol. 9, no. 5, pp. 525-536, 2014.

[15] J. Wu, Z. Luo, Y. Zhang, and N. Zhang, "An interval uncertain optimization method for vehicle suspensions using Chebyshev metamodels," Applied Mathematical Modelling, vol. 38, no. 1516, pp. 3706-3723, 2014.

[16] Y. Kang, W. Zhang, and S. Rakheja, "Relative kinematic and handling performance analyses of independent axle suspensions for a heavy-duty mining truck," International Journal of Heavy Vehicle Systems, vol. 22, no. 2, pp. 114-136, 2015. 


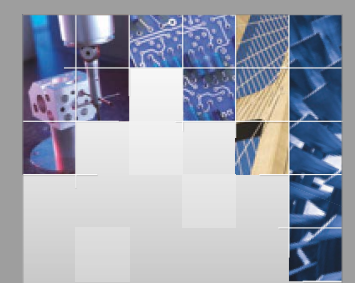

\section{Enfincering}
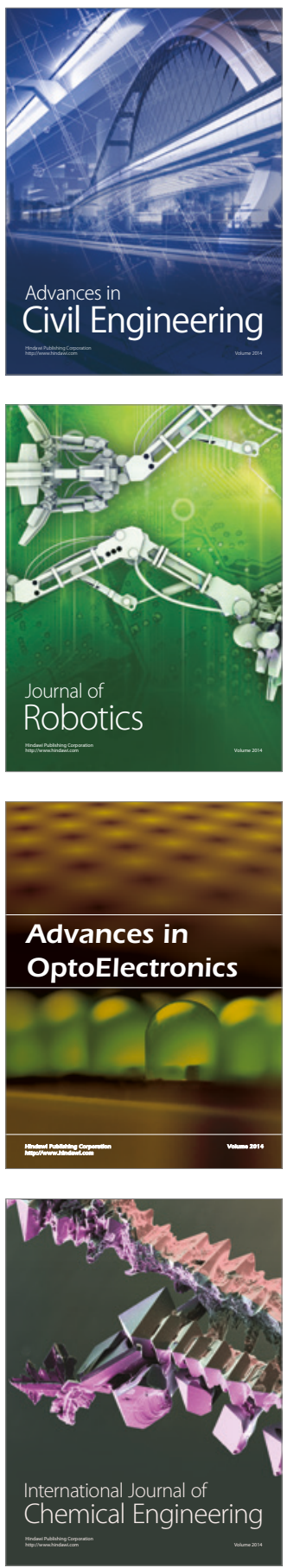

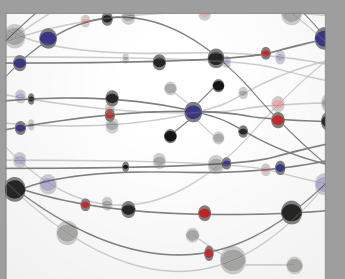

The Scientific World Journal

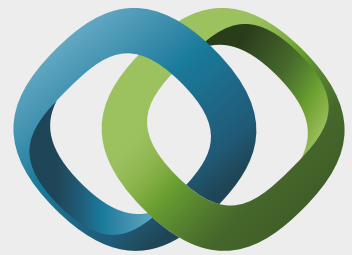

\section{Hindawi}

Submit your manuscripts at

https://www.hindawi.com
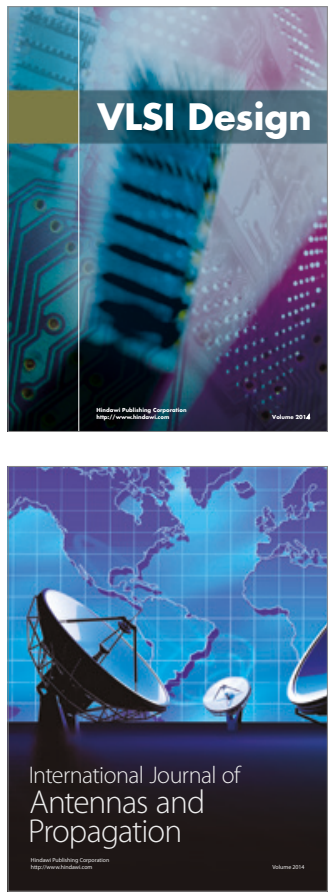

\section{Rotating}

Machinery
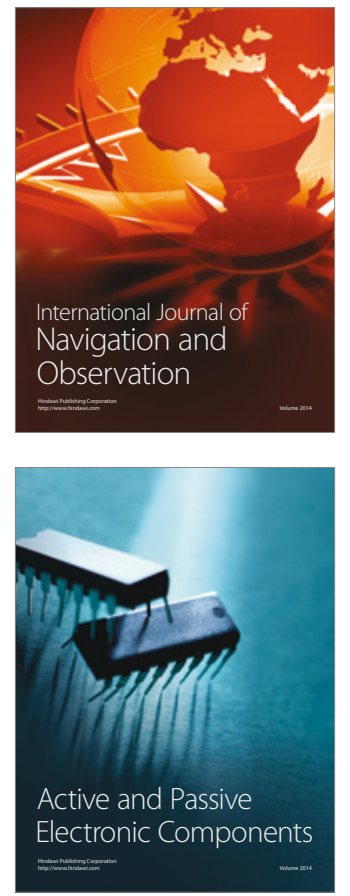
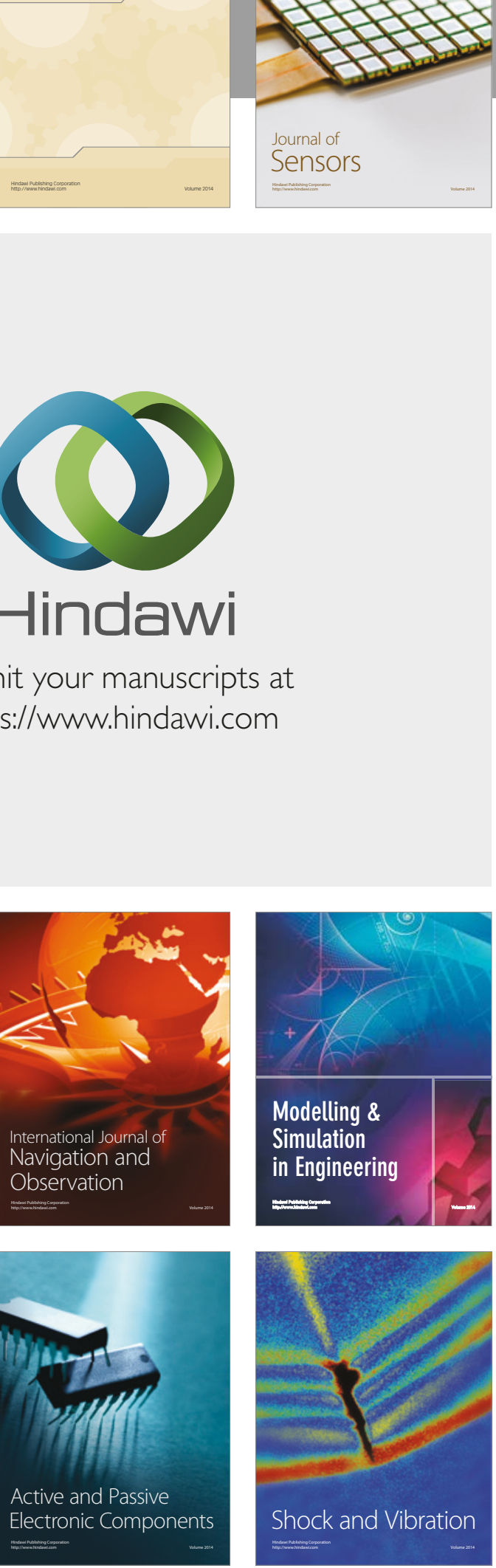
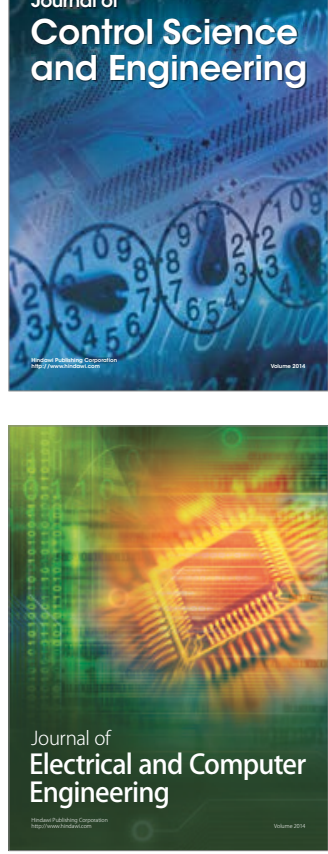

Distributed

Journal of

Control Science

and Engineering
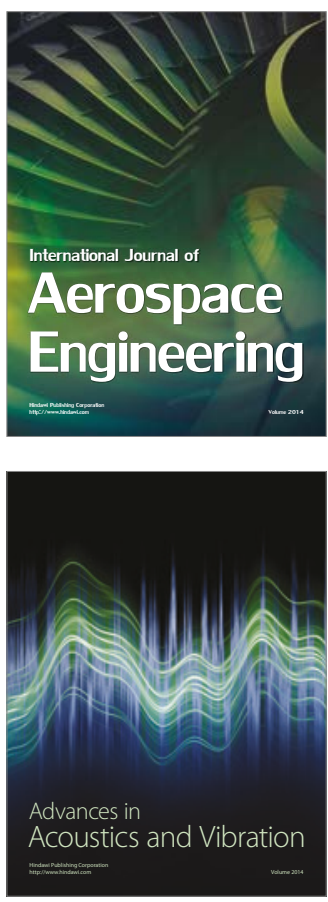

Sensor Networks 